\title{
Integração de Três Conceitos: Função Executiva, Memória de Trabalho e Aprendizado
}

\author{
Carlos Alberto Mourão Junior ${ }^{1}$ \\ Luciene Bandeira Rodrigues Melo \\ Universidade Federal de Juiz de Fora
}

\begin{abstract}
RESUMO - O presente artigo discute o conceito de função executiva enquanto um processo de integração temporal, envolvendo funções como o ajuste preparatório, o controle inibitório e a memória de trabalho. Em seguida questiona o modelo multicomponente de Baddeley para a memória de trabalho e propõe uma nova classificação da função executiva que engloba os modelos de Fuster e de Baddeley. Finalmente revisita o conceito neurobiológico de aprendizado e sugere uma abordagem para se avaliar os déficits de aprendizagem que leve em conta a função executiva como a pedra angular do processo cognitivo.
\end{abstract}

Palavras-chave: função executiva; memória de trabalho; aprendizado; córtex pré-frontal; neuropsicologia.

\section{Integration of Three Concepts: Executive Function, Working Memory and Learning}

\begin{abstract}
This article discusses the concept of executive function as a temporal integration process, involving tasks like preparatory adaptation, inhibitory control and working memory. Next, Baddeley's multicomponent model for working memory is criticized and a new classification of executive function is proposed which incorporates both the model of Fuster as well as that of Baddeley. Finally, this paper revisits the neurobiological concept of learning and suggests an approach to appraise the learning deficits that take into account the executive function as the cornerstone of the cognitive process.
\end{abstract}

Keywords: executive function; working memory; learning; prefrontal cortex; neuropsychology.

Ao contrário da maioria dos textos, preferimos utilizar o termo função executiva no singular, para evitar confusões e ambiguidades conceituais. Naturalmente existem diversas funções executivas, como existem diversas modalidades de memória, diversas modalidades de linguagem ou de atenção, apesar dessas funções cognitivas normalmente serem citadas no singular. Por esse motivo, falaremos em função (e não em funções) executiva, imaginando a mesma como um sistema gerenciador que tem como atributo organizar uma sequência de ações a fim de atingir um objetivo definido.

A função executiva do cérebro vem sendo definida como um conjunto de habilidades, que de forma integrada, possibilitam ao indivíduo direcionar comportamentos a objetivos, realizando ações voluntárias. Tais ações são auto-organizadas, mediante a avaliação de sua adequação e eficiência em relação ao objetivo pretendido, de modo a eleger as estratégias mais eficientes, resolvendo assim, problemas imediatos, e/ou de médio e longo prazo (Capovilla, Assef, \& Cozza, 2007; Malloy-Diniz, Sedo, Fuentes, \& Leite, 2008; Santos, 2004). A função executiva é requerida sempre que se faz necessário formular planos de ação ou quando uma sequência de respostas apropriadas deve ser selecionada e esquematizada. Do ponto de vista da neuropsicologia a função executiva compreende os fenômenos de flexibilidade cognitiva e de tomada de decisões. Atualmente é sabido que os módulos corticais responsáveis pelas funções executivas se localizam nos lobos frontais direito e esquerdo.

1 Endereço para correspondência: Departamento de Fisiologia - ICB. Universidade Federal de Juiz de Fora. Juiz de Fora, MG. CEP: 36036900. Fone: (32) 2102-3211. E-mail: camouraojr@gmail.com
Os primeiros estudos de neurologia continham descrições elaboradas das funções desempenhadas por várias partes do cérebro, contudo, pouco se conhecia acerca da fisiologia dos lobos frontais. Muito tempo se passou até que os neurocientistas pudessem atentar para a importância dos lobos frontais para a cognição. O cérebro é formado por componentes distintos que desempenham diferentes funções, contudo, os lobos frontais não são dotados da especificidade de apresentar uma função única, prontamente classificável. Assim, por muito tempo, foram considerados "lobos silenciosos" (Goldberg, 2002). Mas, em 1848, o acidente com o jovem Phineas Gage, que teve o crânio atravessado por uma barra de ferro em uma explosão, da qual sobreviveu, permanecendo lúcido nas horas que se seguiram ao acidente, trouxe voz aos lobos silenciosos. Embora a barra de ferro tenha atravessado e destruído a parte anterior do cérebro, o jovem Gage podia tocar, ouvir, sentir, falar e movimentar seus músculos; entretanto sua personalidade havia se modificado drasticamente. Ele passou a se mostrar incapaz de se adaptar às normas, e nunca mais foi o mesmo (Damasio, 1996). A história de Gage trouxe luz ao entendimento da fisiologia do lobo frontal ao sugerir que:

“... existiam sistemas no cérebro humano mais dedicados do que quaisquer outros às dimensões pessoais e sociais do raciocínio. A observância de convenções sociais e regras éticas previamente adquiridas poderia ser perdida como resultado de uma lesão cerebral, mesmo quando nem o intelecto de base nem a linguagem se mostrassem comprometidos [...] algo no cérebro estava envolvido especialmente em propriedades 
humanas únicas, e entre elas se encontrava a capacidade de antecipar o futuro e de elaborar planos, de acordo com essa antecipação, no contexto de um ambiente social complexo; o sentido de responsabilidade perante si próprio e perante os outros; a capacidade de orquestrar deliberadamente sua própria sobrevivencia sob o comando do livre-arbitrio". (Damasio, 1996, pp.30-31).

A função exercida pelos lobos frontais parece ser mais metacognitiva do que propriamente cognitiva, uma vez que não se refere a nenhuma habilidade mental específica, porém abrange todas elas. Por esta razão, a função dos lobos frontais é chamada de função executiva. Especificamente o córtex pré-frontal - região filogeneticamente mais moderna do cérebro humano, que compreende as regiões do lobo frontal anteriores ao córtex motor primário - desempenha um papel essencial na formação de metas e objetivos, e no planejamento de estratégias de ação necessárias para a consecução destes objetivos, selecionando as habilidades cognitivas requeridas para a implementação dos planos, e coordenando as mesmas para aplicá-las na ordem correta (Fuster, 2008). Além disso, o córtex pré-frontal é o responsável pela avaliação do sucesso ou fracasso das ações dirigidas a objetivos estabelecidos. (Goldberg, 2002).

Nos primatas, humanos ou não, o córtex pré-frontal é anatomicamente dividido em três regiões: lateral, medial e orbital. Cada região é subdividida em diferentes áreas da citoarquitetura pré-frontal, organizadas em mapas, como os mapas de Brodmann. Contudo, não é possível atribuir eventuais funções fisiológicas para tais áreas, exceto a área 8 que é, em grande parte, dedicada ao controle do movimento ocular. Assim, uma vez que não pode ser funcionalmente subdividido em função de sua citoarquitetura, admite-se que o córtex pré-frontal realize, como um todo, seu papel na organização do comportamento e nas ações cognitivas.

O córtex pré-frontal é excepcionalmente bem conectado a outras estruturas cerebrais (corticais e subcorticais), e suas três regiões são mutuamente conectadas entre si, e com os núcleos anterior e dorsal do tálamo. As regiões medial e orbital, adicionalmente, são conectadas ao hipotálamo e outras estruturas límbicas, sendo que algumas dessas ligações são indiretas, ocorrendo por intermédio do tálamo. A região lateral envia conexões aos núcleos da base (estriado), além de ser profusamente conectada às regiões de associação dos córtices occipital, temporal e parietal. O papel funcional preciso das conexões do córtex pré-frontal não é totalmente conhecido, mas pode ser inferido a partir do papel funcional das estruturas às quais ele se liga. Por exemplo: as conexões pré-frontal / áreas límbicas estão envolvidas no controle do comportamento emocional, ao passo que as ligações pré-frontal / estriado estão envolvidas na coordenação e no planejamento do comportamento motor.

Fuster (2003) postulou que a função executiva opera por meio de redes neurais interativas e sobrepostas, distribuídas nos córtices de associação (principalmente o córtex pré-frontal). Essas redes, denominadas cognitos, alimentam o ciclo percepção-ação, constituindo assim as unidades básicas do processamento executivo.

As conexões recíprocas do córtex pré-frontal lateral com o hipocampo e com o córtex parietal posterior são especialmen- te importantes para os aspectos cognitivos de todas as formas de comportamento. Por intermédio dessas conexões, torna-se possível a mais importante função do córtex pré-frontal, que é a integração temporal de ações para o cumprimento de metas. Aqui o verbo integrar tem o significado de incluir, excluir e organizar elementos em um conjunto, formando um todo coerente. $\mathrm{O}$ processo neural de integrar as informações ao longo da linha do tempo, por intermédio da ordenação dos cognitos, é a base para a programação temporal das ações. A organização temporal de novas e complexas sequências de comportamento se dá por meio da integração de estímulos externos (sensoriais) e estímulos internos (memórias armazenadas). Em outras palavras, a integração temporal nada mais é do que o processamento (análise e síntese) dos estímulos que chegam ao cérebro (tempo presente) e das memórias armazenadas (tempo passado). Em virtude de sua especialização na estruturação temporal de novas e complexas séries de ações direcionadas a objetivos (sob a forma de comportamento, fala ou raciocínio), além da participação na escolha entre as alternativas e nas tomadas de decisão, o córtex pré-frontal pode ser considerado o centro executivo do cérebro (Fuster, 2002).

Para desempenhar esse papel integrativo, o córtex pré-frontal precisa ter acesso a todos os itens de informação sensorial, motora, e mnemônica que dão forma à estrutura do comportamento. A execução do comportamento temporalmente estruturado seria, deste modo, o resultado da ativação de um comando central e da ativação oportuna dos componentes de suas redes neurais. Fuster (2002) relata um experimento com macacos cuja tarefa exigia a integração temporal de diferentes modalidades de estímulos associados. Os resultados deste experimento indicam que, durante o desempenho de uma tarefa de integração temporal, os neurônios no córtex pré-frontal associam estímulos, ao longo do tempo, oriundos das informações sensoriais, de acordo com as regras que uma tarefa sequencial exige. A partir deste resultado o autor propõe que os neurônios por ele estudados são parte das redes da memória de longo prazo que ganharam forma pela aprendizagem da tarefa, e que as redes neurais são ativadas durante a tarefa a fim negociar contingências transtemporais entre os estímulos sensoriais associados.

Para fins exclusivamente didáticos, a função executiva de integração temporal do córtex pré-frontal pode ser subdividida em três funções cognitivas: ajuste preparatório, controle inibitório e memória de trabalho. Uma análise psicológica e fisiológica do funcionamento das três regiões anatômicas pré-frontais (lateral, medial e orbital) produz a seguinte correspondência topográfica das funções cognitivas: as três regiões pré-frontais estão envolvidas em um ou outro aspecto da atenção; a região medial e o giro cingulado anterior estão envolvidos na movimentação e na motivação; a região lateral se relaciona com o ajuste preparatório e com a memória de trabalho, e a região orbital (e, de certa forma, também a medial) se relaciona com o controle inibitório de impulsos e interferências (Fuster, 2008). Passaremos agora a discutir as três funções cognitivas que, juntas, formam o tripé que sustenta o processo de integração temporal.

O ajuste preparatório é uma função prospectiva (dirigida para o futuro), sediada no córtex pré-frontal lateral, que pre- 
para o organismo para as ações dependentes das informações recebidas. Esta função de ajuste do córtex pré-frontal lateral pode ser substanciada por evidências eletrofisiológicas. Entre um input sensorial e sua consequente resposta motora, potenciais lentos podem ser gravados na superfície do lobo frontal no ser humano, os quais são relacionados com a duração do tempo de reação e a exatidão da resposta. Deste procedimento pode-se identificar dois tipos de potenciais, embora ambos pareçam ser parte de uma série contínua. $\mathrm{O}$ primeiro é o contingente de variação negativa $(\mathrm{CVN})$, chamado de "onda de expectativa", que é relacionada à necessidade de negociar a contingência transtemporal entre o estímulo e a resposta. $\mathrm{O}$ segundo é o potencial de prontidão $(\mathrm{PP})$, relacionado à preparação de uma ação motora. O CVN tem uma fonte um tanto mais anterior (no córtex pré-frontal), que o PP, que parece se originar nos córtices pré-motor e motor. Ambos os potenciais aumentam de valor com o tempo e parecem refletir a atividade crescente de neurônios subjacentes à execução da resposta. Em pacientes com lesão pré-frontal, o déficit na habilidade de planejar uma ação futura parece refletir a falha da função do ajuste preparatório (Fuster, 2003).

Uma outra função de caráter integrativo temporal do córtex pré-frontal é o controle inibitório, que consiste na capacidade de inibir respostas inadequadas ou respostas a estímulos distratores, que possam interromper o curso efetivo de uma ação ou resposta adequada em curso. Dificuldades relativas ao controle inibitório são, comumente, associadas à impulsividade (Malloy-Diniz et al., 2008). Fuster (2002) afirma que experiências com lesões em modelos animais e também a observação clínica indicam que o mecanismo neural para esta função inibitória reside nas porções medial e orbital do córtex pré-frontal. O objetivo fisiológico desta função é a supressão de entradas internas (por intermédio da memória) e externas (por intermédio dos sentidos) que possam interferir na estruturação do comportamento, do discurso, ou da cognição e que estejam a ponto de serem empreendidas, ou que já estejam em curso. O controle inibitório do córtex pré-frontal - que talvez possa representar um correlato funcional para o conceito de superego - operando através de seus efeitos seletivos (focalização da figura e a inibição do fundo), é essencial para a integridade do sistema atencional. Um dos indicadores do desenvolvimento psicossocial da criança é justamente o estabelecimento progressivo do controle inibitório sobre os impulsos internos, sobre o sensório, e sobre a mobilidade. Na medida em que a criança cresce, os dois componentes principais da atenção - inclusivo e exclusivo - vão amadurecendo gradualmente, e a criança se torna mais capaz de focalizar e de concentrar a atenção nas tarefas em curso, se tornando, por conseguinte, menos distratível, menos impulsiva, e mais capaz de exercer seu autocontrole.

Por fim, mas não menos importante, outro mecanismo de caráter integrativo temporal é a memória de trabalho. $\mathrm{O}$ conceito teórico mais comum de memória de trabalho diz que a mesma se trata de um sistema de capacidade limitada, que mantém e armazena informações temporariamente, de modo a sustentar os processos de pensamento humano, fornecendo uma interface entre percepção, memória de longo prazo e ação. Em virtude de sua importância, passaremos agora a discutir a memória de trabalho com mais detalhes.

\section{Memória de trabalho}

O conceito de memória de trabalho (MT), talvez seja um dos tópicos que mais provoca confusão e divergências na neurociência em geral, e na neuropsicologia em particular. Um ponto consensual é que a MT é um sistema de memória ultrarrápida (dura poucos segundos), que tem a capacidade de reter uma sequência de 5 a 9 dígitos - o suficiente para gravarmos um número de telefone até efetuarmos a discagem, esquecendo o número logo em seguida. Já com relação à classificação e aos substratos neurais da MT as opiniões são um tanto discordantes. Vamos expor a maneira pela qual nós entendemos a MT enquanto fenômeno, e apresentaremos nossas justificativas para nosso ponto de vista, sem contudo, termos qualquer pretensão de esgotar o assunto ou afirmar que nosso olhar sobre a questão é mais correto do que outros existentes.

Se considerarmos memória como sendo o armazenamento de informações, podemos, para fins didáticos, dividir funcionalmente a memória em dois tipos principais: memória de arquivo e memória de trabalho (Mourão-Júnior, no prelo). A memória de arquivo se forma por intermédio de alterações bioquímicas, produzidas em receptores neuronais, que tornam os neurônios facilitados. Nesse caso formam-se pequenos "arquivos" sinápticos de informações conhecidos como traços de memória ou engramas. Os traços são fragmentos de informações que, após serem consolidados no hipocampo, ficam localizados em redes neurais mais ou menos difusas no córtex cerebral. Esses traços bioquímicos podem durar pouco tempo (se as sinapses não forem reforçadas), ou durar anos, e até mesmo a vida toda, desde que as redes neurais envolvidas sejam constantemente estimuladas. A memória de arquivo, a qual fica seriamente afetada nas demências, representa nosso conhecimento semântico e o conhecimento que temos acerca de nossa autobiografia.

Já a MT é um sistema que armazena as informações somente enquanto uma determinada tarefa (trabalho) está sendo realizada. A MT se dá por meio de um fenômeno elétrico, onde determinadas coletividades de neurônios permanecem disparando potenciais de ação durante alguns segundos, retendo temporariamente a informação, somente durante o tempo em que a mesma é necessária, extinguindo-a logo em seguida (Goldman-Rakic, 1995). Esse tipo de fenômeno tem duração extremamente efêmera (segundos) e não forma traços bioquímicos.

Desde o século XIX a literatura vem falando em memórias de longa e de curta duração (Hebb, 1949; James, 1952), porém termo "memória de trabalho" surgiu na década de 1960, no contexto das teorias do processamento da informação. As menções mais antigas a experimentos sobre MT, ainda não assim denominada, podem ser encontradas até há 100 anos atrás, quando foram descritos experimentos do córtex pré-frontal, concluindo que o mesmo era importante para processos cognitivos (Cowan, 2005).

Há muitas abordagens no estudo da MT que se valem de uma série de recursos empíricos e teóricos. Embora haja essa diversidade, a maioria das teorias concorda que a MT se trata de um sistema de atenção de capacidade limitada, complementado por sistemas de armazenamento localizados mais perifericamente (Baddeley, 2003). Neste sentido, Fuster (2002) argumenta que a MT consiste essencialmente na ativa- 
ção provisória de uma rede cortical extensamente distribuída (cognitos). Seu argumento é baseado na evidência de que, durante a retenção em curto prazo de uma dada informação sensorial para uma ação em perspectiva, neurônios dentro dessas áreas sensoriais do córtex sustentam a ativação. Além disso, a memória de trabalho, para um dado estímulo, pode produzir a ativação neuronal sustentada em diversas áreas do córtex ao mesmo tempo.

Dentre as distintas, porém complementares, abordagens da MT, três se destacam: a) a que dá ênfase ao papel do controle da atenção na memória; b) a que tenta explicá-la nos termos dos modelos originalmente desenvolvidos para o estudo da memória a longo prazo, e c) a que correlaciona as diferenças individuais e os diferentes componentes da MT (Atkinson \& Shiffrin, 1971; Baddeley, 1992; Ericsson \& Kintsch, 1995). Contudo, o mais avançado modelo proposto em humanos integra todas esta abordagens e as aperfeiçoa, trata-se do modelo multicomponente de Baddeley, que se baseia na observação de pacientes que sofreram lesões em diferentes áreas cerebrais e passaram a apresentar déficits em diferentes "nuanças" da MT.

Como a atenção é pré-requisito para o armazenamento temporário de uma informação, Baddeley propôs que a MT depende de um sistema atencional de supervisão, que ele denominou executivo central. Na realidade o executivo central parece ter função análoga ao controle inibitório, proposto por Fuster e já discutido anteriormente. Apesar do executivo central ser considerado um dos elementos principais do modelo multifuncional da MT, é importante deixar claro que ele não armazena nenhum tipo de informação (Baddeley, 2007), logo, talvez possamos considerá-lo apenas um pré-requisito para que a MT se dê. Consideraremos então que o modelo multicomponente da MT proposto por Baddeley é composto por três componentes: uma alça fonológica, um esboço visuoespacial, e um buffer episódico. Cada um destes componentes será detalhado a seguir.

A alça fonológica armazena informações verbais e acústicas utilizando um armazenamento temporário que se mantém por alguns segundos e recicla essas informações através de um subcomponente - a alça articulatória. A informação fonética contida no armazenador fonológico (palavras que ficam ressoando em nosso pensamento) perde-se em poucos segundos, a não ser que a alça articulatória a mantenha através de reverberação (repetição subvocal ou então em voz alta). Assim, vestígios de memória podem ser recuperados e rearticulados, porém tal memória imediata tem um tempo limitado porque a articulação ocorre em tempo real, ou seja, conforme a número de itens ensaiados aumenta há um ponto em que o primeiro item se desvanecerá antes que possa ser evocado. A alça fonológica é fundamental para a coerência do discurso e para a compreensão da fala, pois para compreendermos o enredo de uma história que ouvimos, apesar de não conseguirmos gravar todas as palavras, nosso cérebro grava as cinco ou seis últimas palavras, para que possamos compreender o encadeamento do que foi dito.

Tal como seu equivalente verbal (a alça fonológica), o esboço visuoespacial tem uma limitada capacidade de armazenamento, que se restringe tipicamente a três ou quatro objetos. Por analogia com o papel da alça fonológica na aquisição de linguagem, parece plausível supor que o esboço visuoespacial pode ter um papel na aquisição do conhecimento semântico referente à aparência dos objetos ou à maneira de usá-los. O esboço visuoespacial parece ser importante também para a compreensão de sistemas complexos - tais como máquinas, bem como para a orientação espacial e o conhecimento geográfico. Além disso, o esboço visuoespacial é indispensável à leitura, pois apesar de não "fotografarmos" na memória todas as palavras que lemos em um texto, para compreendê-lo de forma coerente é necessário que o cérebro retenha as quatro ou cinco últimas palavras lidas.

Inicialmente o modelo multicomponente contava só com a alça fonológica e o esboço visuoespacial, porém permanecia uma lacuna que pudesse associar estes dois componentes da MT à memória de longo prazo (memória de arquivo). Além disso, nenhuma relação da MT com a consciência havia sido estabelecida. Deste modo, um novo componente - o buffer episódico - foi agregado ao modelo de modo a dar conta das questões não explicadas pelos mecanismos anteriormente descritos. O termo "buffer" é oriundo da computação, e significa memória temporária.

O buffer episódico é um sistema de armazenamento de capacidade limitada, sendo responsável pela integração de informações, tanto dos componentes visual e verbal quanto da memória de longo prazo, em uma representação episódica única. Utilizando um trocadilho podemos dizer que o buffer episódico é um componente da memória de trabalho que opera trabalhando com memórias. Nesse sentido, parece que o buffer é fundamental também para a evocação das memórias de arquivo, já que durante esse processo os traços de memória são reunidos no buffer episódico, para em seguida serem organizados e editados no córtex pré-frontal, para finalmente as lembranças emergirem em nossa consciência.

Na realidade a MT - apesar de ser condição indispensável para os processos de leitura, linguagem e pensamento -, nada mais é do que um sistema de armazenamento lábil e ultrarrápido de informações. Assim sendo, para testar a MT, tanto em humanos como em animais, basta testar a capacidade de retenção de algumas poucas informações durante poucos segundos. Apesar da MT ser uma condição necessária para a integração temporal, que caracteriza a função executiva, ela não é uma condição suficiente. É importante lembrar que a função executiva é muito mais do que somente a MT e que, para testar a função executiva é preciso utilizar situações reais que sejam capazes de avaliar o processo de integração temporal como um todo. Existem baterias de testes específicas para esse fim.

Parece ainda haver uma certa confusão conceitual entre alguns pesquisadores, que acabam por considerar a função executiva e a memória de trabalho como sinônimos. Tal confusão pode gerar problemas metodológicos, pois os testes simples de memória são insuficientes para avaliar a função executiva. Como diferentes estágios da solução de um problema pode requerer diferentes tipos de informação, os lobos frontais precisam, de forma constante e célere, tornar novas memórias disponíveis "online", se desfazendo, ao mesmo tempo de memórias antigas, liberando, desta maneira, espaço para a utilização de novos dados. Assim, ao invés de memorizar um conjunto estático de informações (como nos testes de memória), o sujeito precisa ser capaz de atualizar rapidamente o conteúdo de sua memória de forma contínua. 
A função executiva (que inclui a MT), cumpre este papel, e seu mau funcionamento compromete a manutenção da tarefa cognitiva de ordenar as informações de forma coerente ao longo do tempo. O interessante é que, embora o córtex pré-frontal seja indispensável para acessar e ativar a informação relevante para uma dada tarefa, muitas vezes ele próprio não contém tal informação; outras partes do cérebro a contém, e o córtex pré-frontal apenas as solicita (Goldberg, 2002).

Apesar de reconhecermos o grande mérito de Baddeley ao propor seu modelo multicomponente, acreditamos que talvez o próprio Baddeley, ao incluir como principal componente de seu modelo o executivo central - que ele próprio afirma ser incapaz de armazenar informação -, possa ter produzido a possível confusão conceitual que ainda paira sobre a MT. Afinal, se considerarmos que o que define o termo memória é exatamente a capacidade de armazenar informações, como pode um modelo de memória ter como principal componente um executivo central que nada mais é do que um elemento atencional incapaz de estocar informação? Talvez a intenção de Baddeley tenha sido criar um modelo para a função executiva como um todo, e não unicamente para a MT. O que efetivamente funciona como memória (bancos de dados) em seu modelo são os três armazenadores ultrarrápidos de informações visuais, verbais e episódicas.

Sugerimos, do ponto de vista conceitual, chamar de memória somente aquilo que de fato for memória. Assim sendo propomos então a seguinte classificação (Figura 1): mesclando o modelo proposto por Fuster com o proposto por Baddeley, podemos dizer que a função executiva do cérebro é representada pela integração temporal. A integração temporal se subdivide nas seguintes funções: i) ajuste preparatório, ii) controle inibitório e iii) memória de trabalho. A memória de trabalho, por sua vez, compreende três componentes: i) alça fonológica, ii) esboço visuoespacial e iii) buffer episódico.

\section{Aprendizado}

O aprendizado é uma função neural muito antiga do ponto de vista filogenético, tanto é que os primeiros experimentos que determinaram suas bases moleculares e renderam o prêmio Nobel ao cientista Eric Kandel foram realizados em um molusco - a lesma do mar (Aplysia sp.).

Podemos definir o aprendizado como a modificação de um comportamento que ocorre em resposta a uma pressão exercida pelo meio. Dentro dessa linha de raciocínio, a principal característica do aprendizado é a aquisição de uma determinada informação. Em animais essa aquisição é determinada

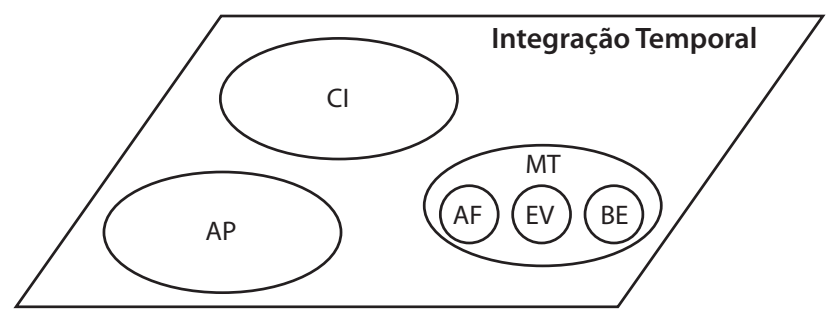

Figura 1. Esquema representando a trilogia que compõe a função executiva (integração temporal). $\mathrm{CI}=$ controle inibitório; $\mathrm{AP}=$ ajuste preparatório; $\mathrm{MT}$ = memória de trabalho; $\mathrm{AF}=$ alça fonológica $\mathrm{EV}=$ esboço visuoespacial; $\mathrm{BE}=$ buffer episódico. pela intensidade dos estímulos, e nos humanos ela está ligada a fatores como estado emocional e motivação (LeDoux, 2001). Entretanto, tanto nos animais como nos seres humanos podemos identificar duas modalidades de aprendizado: o aprendizado não-associativo (habituação e sensibilização) e o aprendizado associativo (ou condicionamento). $\mathrm{O}$ condicionamento pode ainda ser o condicionamento clássico, onde se aprende a responder a estímulos anteriormente ineficazes (Pavlov, 1980), ou o condicionamento operante, onde um novo comportamento é aprendido através de reforço ou punição (Skinner, 1969).

É interessante observar que, ao longo da escala evolutiva, as formas de aprendizado são exatamente as mesmas, desde os invertebrados até nós, humanos. As informações aprendidas ficarão mais ou menos tempo retidas, dependendo dos reforços que receberem, e caso não sejam reforçadas, se extinguem (Hebb, 1949). Karl Lashley ficou conhecido pelos seus experimentos com ratos, mostrando que os animais, após várias sessões diárias de treino, eram capazes de aprender a sair de um labirinto complexo de quatro filas, sem cometer nenhum tipo de erro, mesmo após esses ratos terem várias partes do córtex cerebral retiradas cirurgicamente (Lashley, 1963).

Parece que o que existe de diferente entre os diversos animais no que se refere ao aprendizado é a capacidade de reter e evocar as informações aprendidas, ou seja, o que difere talvez não seja o aprendizado em si, mas sim os sistemas de memória e como eles são gerenciados frente às pressões vindas do entorno (meio). De fato, os resultados apresentados pela neurociência experimental sugerem que o aprendizado se dê em redes neurais altamente plásticas que se auto-organizam em função dos estímulos externos (Kelso, 1995). Isso é evolutivamente justificável, pois, se assim não fosse, talvez não houvesse como as espécies evoluírem se moldando ao meio ambiente (Gallistel, 2000). No ser humano, que representa o ápice da escala evolutiva, as redes neurais que formam a circuitaria do neocórtex são totalmente plásticas, dinâmicas e mutáveis - sinapses se formam e deixam de existir em frações de segundos, durante todo o tempo (Douglas, Markram \& Martin, 2004), permitindo a nós, humanos, um potencial de aprendizado e resiliência talvez muito maior do que imaginamos possuir. Essa capacidade adaptativa profunda e instantânea que apresenta o cérebro humano serve como um possível arcabouço teórico para sustentar as teorias de aprendizagem na criança (Luria, 1981).

Entretanto, já que o aprendizado é algo praticamente inato nas espécies e provavelmente ocorre através de redes neurais difusas, mesmo em espécies animais que sequer apresentam um sistema nervoso central, como poderíamos explicar os déficits de aprendizado, tão comuns em crianças, adolescentes e até adultos?

Vejamos uma possível explicação. Tomando como válida a premissa de que, para as memórias serem evocadas, é imperativa a participação da função executiva (integração temporal), logo, dentro de uma visão construtivista, na interação do sujeito com um objeto, para uma criança aprender, reter, e ser capaz de evocar algum novo conceito, é necessário que ocorra um gerenciamento contínuo de suas memórias já formadas, que irão se moldar e se fundir aos novos conceitos recém adquiridos (Denniston, Savastano, \& Miller, 2001; Garner, 2009; Kandel, Kupfermann \& Iversen, 2000; Smith, \& Jonides, 2003). Prova- 
velmente esse gerenciamento nada mais seja do que a função executiva. Além disso, é provável que as habilidades cognitivas e morais se estruturem de forma paulatina nos períodos pré-operatório e operatório (Piaget, 1987) em função do lento processo de mielinização e amadurecimento que vai sofrendo o córtex pré-frontal durante esse período. Já dentro de uma perspectiva interacionista (Vigotski, 1987), na interação entre sujeitos, provavelmente também seria a função executiva que teria a capacidade de estabelecer a interface entre as memórias já formadas e as informações vindas do meio, através do processo de interação social e do contato interpessoal (Miller \& Wallis, 2003; Sastre-Riba, 2006).

Assim, sugerimos que os déficits de aprendizado talvez sejam, na verdade, déficits executivos, relacionados, portanto, com a atenção, ou com a memória de trabalho, ou com o controle inibitório. Portanto, nos parece ser pouco provável que uma criança ou um adulto apresentem uma dificuldade pura em aprender, já que até os moluscos aprendem, e bem (Squire \& Kandel, 2003). O que supomos estar acontecendo com essa criança ou esse adulto é que eles talvez não estejam conseguindo usar o que aprenderam. Assim sendo, propomos que os sujeitos que apresentem suspeita de "déficit de aprendizagem" sejam submetidos a testes de função executiva, pois talvez aí resida a real origem do problema, e daí possa emergir alguma possibilidade de abordagem terapêutica.

\section{Referências}

Atkinson, R. C., \& Shiffrin, R. M. (1971). The control of short-term memory. Sci Am, 225(2), 82-90.

Baddeley, A. (1992). Working memory. Science, 255(5044), 556559.

Baddeley, A. (2003). Working memory: looking back and looking forward. Nat Rev Neurosci, 4(10), 829-839.

Baddeley, A. (2007). Working memory, thought and action. New York: Oxford University Press.

Capovilla, A. G. S., Assef, E. C. S., \& Cozza, H. F. P. (2007). Avaliação neuropsicológica das funções executivas e relação com desatenção e hiperatividade. Aval psicol, 6(6), 51-60.

Cowan, N. (2005). Working memory capacity. New York: Psychology Press.

Damasio, A. R. (1996). O erro de Descartes: emoção, razão e o cérebro humano. São Paulo: Companhia das Letras, $2^{\mathrm{a}}$ Ed.

Denniston, J. C., Savastano, H. I., \& Miller, R. R. (2001). The extended comparator hypothesis: learning by contiguity, responding by relative strenght. In R. R. Mowrer \& S. B. Klein (Eds.), Handbook of contemporary learning theories. Mahwah: Lawrence Erlbaum.

Douglas, R., Markram, H., \& Martin, K. (2004). Neocortex. In G. M. Shepherd (Ed.), The synaptic organization of the brain. New York: Oxford University Press.

Ericsson, K. A., \& Kintsch, W. (1995). Long-term working memory. Psychol Rev, 102(2), 211-245.

Fuster, J. M. (2002). Frontal lobe and cognitive development. $J$ Neurocytol, 31(3-5), 373-385.

Fuster, J. M. (2003). Cortex and mind: unifying cognition. New York: Oxford University Press.

Fuster, J. M. (2008). The prefrontal cortex (4th ed.). London: Academic Press.
Gallistel, C. R. (2000). The replacement of general-purpose learning models with adaptively specialized learning modules. In M. S. Gazzaniga (Ed.), The new cognitive neurosciences (2nd ed.). Cambridge: MIT Press.

Garner, J. K. (2009). Conceptualizing the relations between executive functions and self-regulated learning. J Psychol, 143(4), 405-426.

Goldberg, E. (2002). O cérebro executivo: lobos frontais e a mente civilizada. Rio de Janeiro: Imago.

Goldman-Rakic, P. S. (1995). Cellular basis of working memory. Neuron, 14(3), 477-485.

Hebb, D. O. (1949). The organization of behavior. New York: Wiley.

James, W. (1952). The principles of psychology. Chicago: William Benton.

Kandel, E. R., Kupfermann, I., \& Iversen, S. (2000). Learning and memory. In E. R. Kandel, J. H. Schwartz \& T. M. Jessell (Eds.), Principles of neural science (4th ed.). New York: McGraw-Hill.

Kelso, J. A. S. (1995). Dynamic patterns: the self-organization of brain and behavior. Cambridge: MIT Press.

Lashley, K. S. (1963). Brain mechanisms and intelligence. New York: Dover Publications.

LeDoux, J. (2001). O cérebro emocional. Rio de Janeiro: Objetiva.

Luria, A. R. (1981). Fundamentos de neuropsicologia. São Paulo: Edusp.

Malloy-Diniz, L. F., Sedo, M., Fuentes, D., \& Leite, W. B. (2008). Neuropsicologia das funções executivas. In D. Fuentes, L. F. Malloy-Diniz, C. H. P. Camargo \& R. M. Cosenza (Eds.), Neuropsicologia: teoria e prática. Porto Alegre: Artmed.

Miller, E. K., \& Wallis, J. D. (2003). The prefrontal cortex and executive brain functions. In L. R. Squire \& F. E. Bloom \& S. K. McConnell \& J. L. Roberts \& N. C. Spitzer \& M. J. Zigmond (Eds.), Fundamental neuroscience (2nd ed.). San Diego: Academic Press.

Mourão-Júnior, C. A. (no prelo). Plasticidade. In C. A. MourãoJúnior \& D. M. Abramov (Eds.), Fisiologia essencial. Rio de Janeiro: Guanabara Koogan.

Pavlov, I. P. (1980). Textos escolhidos. São Paulo: Abril Cultural.

Piaget, J. (1987). O nascimento da inteligência na criança (4⿳a ed.). Rio de Janeiro: LTC.

Santos, F. H. (2004). Funções executivas. In V. M. Andrade \& F. H. Santos \& O. F. A. Bueno (Eds.), Neuropsicologia hoje. São Paulo: Artes Médicas.

Sastre-Riba, S. (2006). Early development and learning conditions: the role of the executive functions. Rev Neurol, 42 Suppl 2, S143-151.

Skinner, B. F. (1969). Contingencies of reinforcement: a theoretical analysis. New Jersey: Prentice-Hall.

Smith, E. E., \& Jonides, J. (2003). Executive control and thought. In L. R. Squire \& F. E. Bloom \& S. K. McConnell \& J. L. Roberts \& N. C. Spitzer \& M. J. Zigmond (Eds.), Fundamental neuroscience (2nd ed.). San Diego: Academic Press.

Squire, L. R., \& Kandel, E. R. (2003). Memória: da mente às moléculas. Porto Alegre: Artmed.

Vigotski, L. S. (1987). Pensamento e linguagem. São Paulo: Martins Fontes.

Recebido em 29.10.2009

Primeira decisão editorial em 21.06.2010

Versão final em 28.07.2010

Aceito em 29.09.2010 